\title{
CONTINUOUS PRODUCTION OF CHITOOLIGOSACCHARIDES BY AN IMMOBILIZED ENZYME IN A DUAL-REACTOR SYSTEM
}

Paloma SANTOS-MORIANO, John M WOODLEY and Francisco J
PLOU*

\section{Published in:}

Journal of Molecular Catalysis B: Enzymatic 133 (2016) 211-217 (DOI: https://doi.org/10.1016/j.molcatb.2016.09.001) 


\section{Continuous production of chitooligosaccharides by an immobilized enzyme in a dual-reactor system}

Paloma SANTOS-MORIANO ${ }^{1}$, John M WOODLEY² and Francisco J PLOU ${ }^{1, *}$

${ }^{1}$ Instituto de Catálisis y Petroleoquímica, CSIC, 28049 Madrid, Spain ${ }^{2}$ Department of Chemical and Biochemical Engineering, Technical University of Denmark, 2800 Lyngby, Denmark

* Corresponding author: Francisco J. Plou, Instituto de Catálisis y Petroleoquímica, CSIC, Cantoblanco, Marie Curie 2, 28049 Madrid, Spain. Fax: +34 91 5854760. Email: fplou@icp.csic.es; http://www.franciscoploulab.eu 


\begin{abstract}
A chitosanolytic activity found in a commercial $\alpha$-amylase from Bacillus amylolyquefaciens (BAN) was covalently immobilized onto glyoxal agarose beads (25\% recovery of activity) and assessed for the continuous production of chitooligosaccharides (COS). The immobilization did not change the reaction profile (with chitotriose and chitobiose as major products, using chitosans of different polymerization and deacetylation degrees), but significantly increased the enzyme thermostability. A two-step process was proposed, in which chitosan was first hydrolyzed in a batch reactor to a viscosity that could flow through a packed-bead reactor (PBR), thus avoiding clogging of the column. The relationship between hydrolysis degree of chitosan $(1 \% \mathrm{w} / \mathrm{v})$ and viscosity of the solution was assessed in a batch reactor. A $50 \%$ hydrolyzed chitosan did not cause any clogging of the PBR. Under these conditions, the productivity of the PBR at the lowest

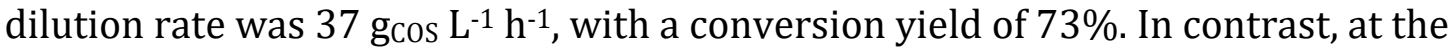
highest dilution rate, the productivity was nearly $200 \mathrm{~g}_{\cos } \mathrm{L}^{-1} \mathrm{~h}^{-1}$, but the conversion yield dropped to around $40 \%$.
\end{abstract}

Keywords: Chitooligosaccharides; Chitosanolytic enzymes; Covalent immobilization; Packed-bead reactor; Glyoxal agarose; Process optimization. 


\section{INTRODUCTION}

Chitosan is a polysaccharide composed of D-glucosamine (GlcN) and Nacetylglucosamine (GlcNAc) moieties with $\beta(1 \rightarrow 4)$ linkages that is obtained by partial deacetylation of chitin, the second most abundant polysaccharide in nature after cellulose [1]. Chitosan is widely used as a biopolymer in the pharmaceutical, cosmetic, textile, and food industries [2], either as a carrier for drugs due to its physicochemical characteristics, or as a preservative because of its antibacterial properties. The biological activities of chitosan depend on its molecular weight (related to the degree of polymerization, DP) and its charge (associated to the deacetylation degree, DD) [3]. However, some of the potential applications of chitosan are limited by its high viscosity and low solubility at neutral $\mathrm{pH}$ [4].

Chitooligosaccharides (COS), obtained by chemical or enzymatic hydrolysis of chitosan, are more soluble and exhibit enhanced biological activities compared with the polysaccharide [5, 6]. COS show antimicrobial, antioxidant, antiangiogenic, antitumoral, anti-inflammatory and prebiotic properties, among others [7-11].

The bioactivity of COS also depends mostly on their DP, DD and pattern of acetylation (PA) which, in turn, depend on the source of chitosan and the hydrolysis strategy. Enzymatic hydrolysis offers significant advantages over chemical methods, especially with respect to the mild conditions employed and the possibility to control the DD, DP and PA of the resulting COS on the basis of the enzyme specificity [12-14]. Chitosanolysis can be catalyzed mainly by chitosanases, but also by other enzymes including exo- $\beta$-glucosaminidases, exo- $\beta$ $\mathrm{N}$-acetylglucosaminidases, chitinases and, non-specifically, by proteases, pectinases, cellulases or lysozyme [15-19].

For the development of a continuous process for COS synthesis, the immobilization of the chitosanolytic enzymes is essential for the separation of the biocatalyst from the reaction mixture, facilitating downstream processes and potential enzyme reuse, which may lead to an overall economic-effectiveness [20]. For this type of enzyme, covalent binding is preferred over simple adsorption because the substrate chitosan possesses an extraordinary ability -partly due to the presence of amino groups- to bind biomolecules, which may cause the desorption of the enzyme from the carrier. In fact, most of the strategies reported to immobilize chitosanases involve the formation of covalent bonds between the enzyme and the carrier, using silica gel [21], agar gel [22, 23], agarose [24], polyacrylonitrile [25], DEAE-cellulose [26], amylose-coated magnetic nanoparticles [27] and even chitin itself [28, 29]. Other methodologies, in particular alginate entrapment, have been also explored $[30,31]$. However, the

Abbreviations: COS, chitooligosaccharides; paCOS, partially acetylated chitooligosaccharides; DD, deacetylation degree; DP, degree of polymerization; ESI, electrospray; GIcN, Dglucosamine; GlcNAc, N-acetyl-glucosamine; $(\mathrm{GlcN})_{2}$, chitobiose; $(\mathrm{GlcN})_{3}$, chitotriose; $(\mathrm{GlcN})_{4}$, chitotetraose; $(\mathrm{GlcN})_{5}$, chitopentaose; HMWC, high molecular weight chitosan; HPAEC, highperformance anion-exchange chromatography; MS, mass spectrometry; PAD, pulsed amperometric detection; TOF, time-of-flight; BAN-GIx, BAN covalently immobilized on glyoxal agarose beads; PBR, packed-bed reactor; CSTR, continuous stirred tank reactor; $d$, dilution rate. 
continuous production of COS with immobilized chitosanases has been scarcely studied [32-34].

Chitosan is a non-Newtonian viscous polymer, which adds a difficulty to the design of processes for the production of COS [35]. Some approaches have been proposed to overcome this limitation, but the problem of viscosity has not been entirely solved, leading to low productivities [36-39]. For example, Ming and coworkers immobilized a chitosanase on an agar gel-coated multidisc impeller, and obtained yields of between $20-45 \%$ for the addition of chitopentaose and chitohexaose, depending on the surface activity of the enzyme [23]. Jeon and Kim set up a dual reactor system with a packed-bed reactor (PBR) to decrease viscosity of chitosan followed by an ultrafiltration membrane reactor to produce COS of the desired DP [33].

The hydrolysis of chitosan is not the only case where the viscosity of the substrate represents a hurdle for engineering a process. In the context of biorefineries [40], the high viscosity of the feed solution (starch, cellulose, hemicellulose, etc.) limits the implementation of fixed-bed bioreactors for the continuous hydrolysis of the biopolymers [41]. However, continuous processes would enable control to a much greater extent and, in particular, to change the degree of hydrolysis by adjustment of the flowrate, and hence residence time. Recently, Rakmai and Cheirsilp proposed a dual reactor system for the production of $\beta$-cyclodextrin, composed of a continuous stirred tank reactor (CSTR) for reduction of viscosity of liquefied starch, followed by a PBR with a productivity of $3.98 \mathrm{~g} \mathrm{~L}^{-1} \mathrm{~h}^{-1}$ [42]. On this basis we argued that this strategy could also serve as a model for the production of COS.

In this work, we report the characterization of a chitosanolytic activity found in a commercial $\alpha$-amylase from Bacillus amylolyquefaciens (BAN). The enzyme was covalently immobilized onto glyoxal agarose beads and assessed both in batch and fixed-bed reactors for continuous production of COS. 


\section{MATERIALS AND METHODS}

\subsection{Enzyme and reagents}

BAN 480L ( $\alpha$-amylase from Bacillus amylolyquefaciens) was kindly donated by Novozymes (Bagsvaerd, Denmark). High Density Glyoxal 4BCL (spherical, 50-150

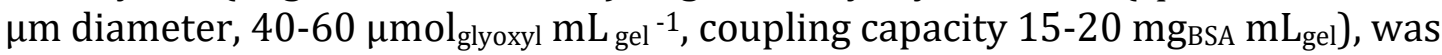
purchased from Agarose Bead Technologies (Miami, FL, USA). Chitosan QS1 (98.5 $\mathrm{kDa}, 81 \%$ DD) was kindly provided by InFiQus (Madrid, Spain). Chitosan CHIT100 (100-300 kDa, DD $\geq 90 \%)$ and CHIT600 (600-800 kDa, DD $\geq 90 \%)$ were acquired from Acros Organics (Thermo Fischer Scientific Inc., Waltham, MA, USA). DGlucosamine (GlcN) and N-acetyl-glucosamine (GlcNAc) were purchased from Sigma-Aldrich (St. Louis, MO, USA). Fully deacetylated COS with DP from 2 to 5, and fully acetylated COS with DP from 2 to 4 were purchased from Carbosynth Ltd. (Berkshire, UK). All other reagents were of the highest purity grade.

\subsection{Activity assays}

Chitosanolytic activity was determined by detection of reducing sugars with a modified 3,5-dinitrosalicylic acid (DNS) method. For the soluble enzyme, and prior to the assay, low-molecular-weight contaminants in the commercial sample were removed with a DP-10 desalting column (GE Healthcare, Uppsala, Sweden). Activity assays were performed in $1.5 \mathrm{~mL}$ centrifuge tubes by adding $200 \mu \mathrm{L}$ of enzyme to $800 \mu \mathrm{L}$ of $1 \%(\mathrm{w} / \mathrm{v})$ chitosan CHIT100 dissolved in $50 \mathrm{mM}$ sodium acetate buffer ( $\mathrm{pH} 5.0$ ). Tubes were incubated at $50^{\circ} \mathrm{C}$ and $900 \mathrm{rpm}$ in a Thermo Shaker TS-100 (Boeco, Hamburg, Germany) and reactions were stopped by addition of $0.25 \mathrm{M} \mathrm{NaOH}$ in a $1 / 1(\mathrm{v} / \mathrm{v})$ ratio. The addition of $\mathrm{NaOH}$ also caused the precipitation of the remaining polysaccharide, which was removed by centrifugation at 5,000 $\mathrm{x}$ g for $10 \mathrm{~min}$.

For the immobilized enzyme, the activity assay was carried out following a method developed in our laboratory that involves the use of filtered microcentrifuge tubes [43]. 50-60 mg of immobilized biocatalyst were placed on the filter and $500 \mu \mathrm{L}$ of $1 \%(\mathrm{w} / \mathrm{v}$ ) chitosan CHIT100 dissolved in $50 \mathrm{mM}$ sodium acetate buffer ( $\mathrm{pH}$ 5.0) were added. The reaction was incubated in the same conditions as the soluble enzyme and it was stopped by centrifugation ( $5 \mathrm{~min}$, $5,000 \mathrm{xg}$ ) that separated the substrate from the enzyme. To inactivate the possible leaked remaining? enzyme, $\mathrm{NaOH}$ was added to the supernatant, in the same conditions as above.

In both cases, the quantification of reducing sugars in the supernatant was carried out by the DNS method in a 96-well microplate. A calibration curve of Dglucosamine was done. One unit of activity (U) corresponded to the release of one $\mu \mathrm{mol}$ of reducing sugars per minute.

\subsection{Optimal temperature of soluble enzyme}

For the determination of optimal temperature of the enzyme, a mixture of 20 $\mu \mathrm{L}$ of BAN and $80 \mu \mathrm{L}$ of $1 \%(\mathrm{w} / \mathrm{v}$ ) CHIT100 in $50 \mathrm{mM}$ acetate buffer (pH 5.0) was incubated at different temperatures $\left(35-80^{\circ} \mathrm{C}\right)$ in a thermocycler (BioRad), using PCR microplates. Reactions were stopped by addition of $100 \mu \mathrm{L}$ of $0.25 \mathrm{M} \mathrm{NaOH}$ to each well and the plates were centrifuged for $20 \mathrm{~min}$ at 3,000 x g. The supernatant was transferred to a flat-bottom 96 -well plate and the concentration of reducing 
sugars was measured by the DNS assay. All the experiments were performed in triplicate and the error was expressed as the standard deviation of the three measurements.

\subsection{Enzyme immobilization}

The immobilization of BAN on glyoxal agarose was carried out following the protocol of the supplier with slight modifications. Prior to immobilization, the glyoxal agarose beads were washed with distilled water to remove any preservatives. Simultaneously, contaminants present in the enzymatic preparations were removed with a DP-10 desalting column, and the enzyme was eluted with $100 \mathrm{mM} \mathrm{NaHCO}_{3}$ (pH 10.0), in order to perform immobilization at such $\mathrm{pH}$. The enzyme solution was added to $1 \mathrm{~g}$ of glyoxal agarose and incubated for $1 \mathrm{~h}$ at room temperature in a roller shaker (JP Selecta S.A., Spain). This immobilization time was optimized taking into account the compromise between the formation of covalent bonds and the stability of the enzyme at $\mathrm{pH} 10$. After this incubation, 10 mg of $\mathrm{NaBH}_{4}$ were added for the reductive amination of the Schiff base bonds and the mixture was incubated at room temperature for $30 \mathrm{~min}$ to yield the immobilized biocatalyst BAN-Glx. The immobilization mixture was filtrated with acetate/nitrate cellulose filters ( $0.45 \mu \mathrm{m}$, Merck Millipore, Billerica, MA) to separate the immobilized biocatalyst from the remaining solution. The immobilized biocatalyst was washed thoroughly with $50 \mathrm{mM}$ sodium acetate buffer ( $\mathrm{pH}$ 5.0) in order to remove any loosely adsorbed enzyme.

\subsection{Thermostability of soluble and immobilized enzymes}

The thermal stability of chitosanolytic activity in BAN (soluble and immobilized) was assayed at $50^{\circ} \mathrm{C}$, the optimal reaction temperature. Soluble BAN $(1 \mathrm{~mL})$ or immobilized BAN-Glx ( $300 \mathrm{mg}$ ) was incubated in $50 \mathrm{mM}$ sodium acetate buffer (pH 5.0) at $50^{\circ} \mathrm{C}$ in a rocking incubator (Enviro-genie ${ }^{\circledR}$, Scientific Industries, Inc. USA). Samples were taken at 1 and 2 days and residual activity was measured by the DNS method at the optimal conditions ( $50^{\circ} \mathrm{C}$, $\mathrm{pH} 5.0$ ), as described above. Activity values were compared with the activity before any incubation in the optimal conditions. All the experiments were performed in triplicate and the error was expressed as the standard deviation of the three measurements.

\subsection{COS synthesis and analysis by HPAEC-PAD}

Reactions $(3 \mathrm{~mL})$ were set for both the soluble and the immobilized biocatalysts with $0.5 \%(\mathrm{w} / \mathrm{v}$ ) chitosan (of different MW and DD) as substrate and the same amount of enzyme units $\left(0.05 \mathrm{U} \mathrm{mL}^{-1}\right)$. Aliquots were taken at different times and mixed with $0.25 \mathrm{M} \mathrm{NaOH}$ in a $1 / 1(\mathrm{v} / \mathrm{v})$ ratio to stop the reaction and to precipitate the remaining polysaccharide, which was removed by centrifugation at $5,000 \mathrm{x}$ g for $10 \mathrm{~min}$. The supernatant was diluted with water $(2.5 \mathrm{mM} \mathrm{NaOH}$ final concentration) and analyzed by High Performance Anionic Exchange

Chromatography with Pulsed Amperometric Detection (HPAEC-PAD) on a ICS3000 system (Dionex, Thermo Fischer Scientific Inc., Waltham, MA) consisting of an SP gradient pump, an electrochemical detector with a gold working electrode and $\mathrm{Ag} / \mathrm{AgCl}$ as reference electrode, and an autosampler (model AS-HV). All eluents were degassed by flushing with helium. An anion-exchange Carbo-Pack PA-200 column (4 × $250 \mathrm{~mm}$, Dionex) connected to a CarboPac PA-200 guard column $(4 \times$ 
$50 \mathrm{~mm}$ ) was used at $30^{\circ} \mathrm{C}$. The initial mobile phase was $4 \mathrm{mM} \mathrm{NaOH}$ at $0.3 \mathrm{~mL} \mathrm{~min}^{-}$ 1 for $30 \mathrm{~min}$. Then, column was washed for $20 \mathrm{~min}$ at $0.5 \mathrm{~mL} \mathrm{~min}^{-1}$ with a solution containing $100 \mathrm{mM}$ sodium acetate and $100 \mathrm{mM} \mathrm{NaOH}$, and equilibrated with 4 $\mathrm{mM} \mathrm{NaOH}$. The chromatograms were analyzed using Chromeleon software. The identification and quantification of the different carbohydrates was done on the basis of commercially available standards.

\subsection{Mass spectrometry}

The molecular weight of COS was assessed using a mass spectrometer with hybrid QTOF analyzer (model QSTAR, Pulsar i, AB Sciex). Reaction samples were analyzed by direct infusion and ionized by electrospray (with methanol as ionizing phase) in positive reflector mode.

\subsection{Viscosity measurements}

Viscosity of chitosan CHIT100 in $100 \mathrm{mM}$ sodium acetate buffer pH 5.0 was studied. Experiments were performed with a rheometer (Advanced rheometer AR20) and a conic geometry $\left(6 \mathrm{~cm}, 1^{\circ}\right)$ for small volume samples $(1 \mathrm{~mL})$, and with standard size recessed end concentric cylinder geometry for larger samples (10 $\mathrm{mL}$ ). Results were analyzed with TAData32 software. Viscosity of reaction samples was analyzed without precipitation with $\mathrm{NaOH}$. Instead, the enzyme was inactivated by heating at $95^{\circ} \mathrm{C}$ for $10 \mathrm{~min}$. Considering the fact that chitosan is a non-Newtonian fluid, shear force vs. shear stress flow charts were adjusted to the best fit (Herschel-Bulkley model) and the effective viscosity was calculated.

\subsection{Batch reactor}

A stirred tank reactor with the immobilized enzyme was set in batch with $1.5 \mathrm{U}$ of immobilized biocatalyst and $100 \mathrm{~mL}$ of $1 \%$ (w/v) chitosan (CHIT100) in 100 $\mathrm{mM}$ acetate buffer ( $\mathrm{pH} 5.0$ ) as substrate. The reactor worked at $50^{\circ} \mathrm{C}$ and $400 \mathrm{rpm}$, with magnetic stirring. Samples were taken at different times and the enzyme inactivated by heating at $95^{\circ} \mathrm{C}$ for $10 \mathrm{~min}$. Viscosity and COS content were analyzed as described above.

\subsection{Packed-bed reactor}

A packed bed reactor in a glass column $(\mathrm{d}=1.5 \mathrm{~cm})$ was set up. Paper filter (cut-off 20-25 $\mu \mathrm{m}$ ) was placed at both ends to avoid leakage of the particles. BANGlx (1.5 U) was packed by gravity to a length of $1.8 \mathrm{~cm}$ and then compressed to 1.5 $\mathrm{cm}$. The column was kept at $50^{\circ} \mathrm{C}$ in a water bath. Substrate (partially hydrolyzed chitosan) was pumped using a peristaltic pump at different flow rates. Effect of dilution rate on productivity, conversion yield and continuous production of COS was investigated. Different substrate flow rates of $50 \%$ hydrolyzed $1 \%(\mathrm{w} / \mathrm{v}$ ) chitosan (previously produced in a batch reactor with BAN-Glx) were pumped through the PBR with the aid of a peristaltic pump. When the system was considered to be in steady state, samples were taken and analyzed by HPAEC-PAD. 


\section{RESULTS AND DISCUSSION}

\subsection{Chitosanolytic activity of BAN}

The screening of chitosanolytic activity in several commercially available enzymes was carried out following the release of reducing sugars by the DNS method with 1\% (w/v) CHIT100 as substrate. Among them, BAN (a preparation from Bacillus amyloliquefaciens, whose stated substrate is starch, $\alpha$-amylase activity) showed the highest activity (3.39 $\left.\pm 0.13 \mathrm{U} \mathrm{mL}^{-1}\right)$ and was selected for further experiments. This level of activity is similar to the level described for other chitosanolytic preparations from bacterial strains [44,45]. Protein content in the sample, measured by the Bradford method [46] [using BSA as the calibration standard), was $15 \pm 2 \mathrm{mg} \mathrm{mL}^{-1}$. For several commercial enzymes described in the literature, the stated activity of the sample (e.g. cellulase [16] or pectinase [17]) was identified as the responsible of the chitosanolytic activity. In other cases, as it is likely with BAN, the chitosanolytic activity comes from another minor enzyme in the preparation (see SDS-PAGE gel in Fig. S1).

Optimal temperature of chitosanolytic activity in BAN was assayed and is shown in Fig. 1 . The enzyme displayed the highest activity around $50^{\circ} \mathrm{C}$, like some other chitosanases described in the literature [13].

The profile of COS synthesized using $0.5 \%(\mathrm{w} / \mathrm{v})$ chitosan and $0.05 \mathrm{U} \mathrm{mL}^{-1}$ BAN was analyzed. A representative chromatogram ( $1.5 \mathrm{~h}$ reaction time) is illustrated in Fig. 2. Chitopentaose [(GlcN) $)_{5}$, peak 2] was present at short times, but disappeared with the progress of the reaction. Hydrolysis of $(\mathrm{GlcN})_{5}$ gave rise to chitotriose $\left[(\mathrm{GlcN})_{3}\right.$, peak 4] and chitobiose $\left[(\mathrm{GlcN})_{2}\right.$, peak 5], which were the most abundant COS at the end of the process. Quantification of the identified COS is shown on the left of Fig. 3. Glucosamine (GlcN, peak 1 in Fig. 2) was detected but in very small concentrations, which implies that the enzyme with chitosanolytic activity is mainly an endo-chitosanase/chitinase. The presence of GlcN is generally undesired due to its high unspecific cytotoxicity [47].

The mixtures obtained at the end of the reactions were analyzed by mass spectrometry (MS-ESI). Identification of COS by MS correlated quite well with the HPAEC-PAD analyses, confirming the presence of COS fully deacetylated COS with DP from 2 to 4, and $\mathrm{GlcN}_{3}$ as the major product (Table 1). MS also helped discarding the presence of fully acetylated COS. Besides CHIT100, other chitosans with different DP and DD were assayed as substrates with BAN under the same conditions. Table 1 shows that with chitosan QS1 partially acetylated COS (paCOS) are formed due to the lower DD (81\%) of this chitosan. On the other hand, when using chitosan CHIT600 (DD>90\%), similar products than with CHIT100 were formed. This illustrates the importance of the chitosan source on the final composition of the reaction mixtures. The amount of GlcN with chitosan CHIT600 was slightly higher than with CHIT100, so the latter was selected as the preferred substrate for the production of fully deacetylated COS, mainly (GlcN) $)_{3}$. Chitotriose is an interesting compound because it displays antioxidant [10] and neuroprotective [48] properties.

\subsection{Immobilization of BAN on glyoxal agarose beads}

Considering the large molecular size of chitosan, the immobilization of the chitosanolytic activity should preferably take place on the surface of the carrier, 
either by adsorption or, willingly, by the formation of covalent bonds. Thus, the enzyme was covalently coupled to glyoxal agarose beads, yielding the biocatalyst BAN-Glx. The main immobilization parameters are summarized in Table 2 . The recovery of activity was not very high (25\%) due to several possible reasons. First, covalent immobilization involves the rigidification of the enzyme structure causing some loss of activity [49]. Secondly, the binding can take place in an orientation that hides the active site of the enzyme not allowing the diffusion of chitosan. Finally, the enzyme shows some unstability at the immobilization $\mathrm{pH}(10.0)$. However, the biocatalyst BAN-Glx showed a moderate activity of nearly $3 \mathrm{U} \mathrm{g}^{-1}$.

\subsection{Characterization of BAN-Glx}

The effect of immobilization on enzyme stability, in absence of substrate, was assayed and compared with the soluble enzyme (ig. 4). BAN-Glx was substantially more stable at $50^{\circ} \mathrm{C}(\mathrm{pH} 5.0)$ than the soluble enzyme. A low stability at temperatures $\geq 50^{\circ} \mathrm{C}$ is the typical behavior of most of the characterized chitosanases described in the literature [44]. BAN-Glx conserved around $60 \%$ of its initial activity after 2 days under such conditions. This stabilization effect is typically reported in covalent immobilization [20].

The production of COS by BAN-Glx was analyzed by HPAEC-PAD and MS ESI, and compared with the soluble enzyme. Reactions were performed with $0.5 \%$ $(\mathrm{w} / \mathrm{v})$ chitosan CHIT100 and the same amount of enzyme units $\left(0.05 \mathrm{U} \mathrm{mL}^{-1}\right)$, in a total reaction volume of $3 \mathrm{~mL}$. Fig. 3 (right) indicates that the reaction profiles with free and immobilized biocatalysts were very similar. This fact confirmed that the reaction was probably occurring at the particle surface and thus the immobilized enzyme showed a high effectiveness factor.

In both cases, (GlcN) $)_{5}$ was initially formed and further hydrolyzed to $(\mathrm{GlcN})_{2}$ and (GlcN) $)_{3}$. In order to obtain a product enriched in deacetylated oligosaccharides showing DP $\geq 3$ - whose bioactive properties are reported to be superior compared with chitobiose [50]-, the reaction can be stopped between 1.5 and $2 \mathrm{~h}$. MS-ESI spectra obtained with the three chitosans and BAN-Glx were very similar to the soluble enzyme (Table 1$)$.

In general terms, the immobilization did not change the COS formation kinetics and the product profile, but significantly increased the stability of the enzyme.

\subsection{Batch reactor with BAN-Glx}

A batch stirred tank reactor was set up as described in the Experimental Section. Viscosity and COS concentration were monitored for $60 \mathrm{~h}$ ( $\underline{\text { Fig. 5 }}$ ). Viscosity, related with the presence of HMW chitosan, decreased very fast without significant appearance of COS in the reaction ( Fig. 5B). This fact gives a hint about the specificity of the enzyme, which endo-hydrolyzes the chitosan and therefore decreases the size of the substrate very fast without the appearance of COS oligomers (detected by HPAEC-PAD). Overall productivity of this batch reactor was $1.7 \mathrm{~g}_{\cos } \mathrm{L}^{-1} \mathrm{~h}^{-1}$, which is not particularly high compared with the productivities that can be achieved operating in continuous mode [32-34].

\subsection{Packed-bed reactor with BAN-Glx}

In order to increase productivity, BAN-Glx was packed in a $1 \mathrm{~mL}$ glass column for the continuous production of COS. $1 \%(\mathrm{w} / \mathrm{v}$ ) chitosan (CHIT100) was pumped 
through the PBR at a flowrate of $0.1 \mathrm{~mL} \mathrm{~min}^{-1}$. Unfortunately, due to the high viscosity of chitosan and the compressible nature of the agarose beads, column clogging and further reduction of the flowrate took place, leading finally to reactor shutdown. Based on previous reports by Rakmai and coworkers [42] for the synthesis of $\beta$-cyclodextrins from starch slurry, we considered a two-step process, in which chitosan was first hydrolyzed in a CSTR to a viscosity that could flow through the PBR (Fig. 6).

In order to do so, the critical viscosity that the system could accept was assessed. Theoretical modelling of this specific system is not very straightforward due to two main factors: the non-Newtonian nature of chitosan, which makes it difficult to know the exact value of viscosity in a PBR [51]; and the compressibility of the carrier, which adds another factor to the modelling [52]. Moreover, the agarose carriers swell in aqueous solution, complicating the measurements of particle size and voidage of the column. Taking all this into account, we decided to follow an empirical approach. Different batch reactors were set-up with the immobilized enzyme and reactions were stopped at different degrees of hydrolysis, measured by the reduction in viscosity. Completely hydrolyzed chitosan (defined as degree of hydrolysis of 100\%) was assessed, and likewise hydrolysis levels of $90,85,55$, and $40 \%$ were tested. The partially hydrolyzed chitosan was pumped at a flowrate of $0.2 \mathrm{~mL} \mathrm{~min}^{-1}$ through the PBR. Column clogged after $2 \mathrm{~h}$ with $40 \%$ hydrolyzed chitosan, indicating that the viscosity of this substrate was over the critical value that the column could accept. In contrast, $50 \%$ hydrolyzed chitosan did not cause any clogging and was used for the PBR experiments. We observed that the immobilized enzyme maintained most of its initial activity at least 4 days.

The effect of dilution rate $\left(\mathrm{d}, \mathrm{h}^{-1}\right)$ on productivity and overall yield was studied (Fig. 7) with $1 \%(\mathrm{w} / \mathrm{v}$ ) of $50 \%$ hydrolyzed CHIT100 as substrate ([Chitosan]o), using the following equations:

$$
\begin{aligned}
& \text { Conversion yield }(\%)=\frac{[\text { COS }]}{[\text { Chitosan }]_{0}} \times 100 \\
& \text { Productivity }\left(\mathrm{g}_{\operatorname{Cos}} \mathrm{L}^{-1} \mathrm{~h}^{-1}\right)=[\operatorname{COS}] \times \mathrm{d}
\end{aligned}
$$

At the lowest dilution rate the productivity was $37 \mathrm{~g}_{\cos } \mathrm{L}^{-1} \mathrm{~h}^{-1}$, with a conversion yield of $73 \%$. On the other hand, the highest dilution rate (corresponding to a flow rate of $1 \mathrm{~mL} \mathrm{~min}^{-1}$ ) gave a productivity of nearly $200 \mathrm{~g}$ cos $\mathrm{L}^{-1} \mathrm{~h}^{-1}$, but at the cost of the conversion yield, which dropped to around $40 \%$, as a result of shorter residence time. Regarding product selectivity, the mixture presented a higher content of longer chitooligosaccharides when increasing the dilution rate. A total conversion of chitosan into COS would be desirable in order to eliminate the purification step to remove the residual chitosan. It would be interesting to reduce the dilution rate to the maximum allowable to avoid the use of downstream processes of purification. Nevertheless the principle of the dualreactor seems to work well and productivity and yield obtained in this work are higher than those described in the literature for the continuous production of COS in the PBR alone [22, 34]. 


\section{CONCLUSIONS}

A batch reactor with the immobilized biocatalyst was set and the relationship between hydrolysis and viscosity of chitosan was assayed. We demonstrated that partial hydrolysis of chitosan in a batch reactor caused a significant reduction of viscosity that facilitated the flow of substrate through the PBR, yielding enhanced productivity. This dual-reactor system could represent a good strategy for the continuous production of COS from chitosan, which could be also extrapolated to other biotransformations involving viscous biopolymers such as starch, xylan or cellulose.

\section{Acknowledgments}

We thank Ramiro. Martinez (Novozymes) for supplying BAN and for critical suggestions. We thank Prof. Peter Szabo (DTU, Denmark) for his help with the viscosity measurements. We thank Angeles Heras (InFiQus, Spain) for the kindly supply of chitosan QS1. This work was supported by a grant from the Spanish Ministry of Economy and Competitiveness (BI02013-48779-C4-1-R). We thank COST-Action 310 CM1303 on Systems Biocatalysts for granting P. SantosMoriano a Short Term Scientific Mission. P. Santos-Moriano thanks the Spanish Ministry of Education for FPU grant.

\section{Supporting information}

SDS-PAGE of BAN sample. MS-ESI spectra of BAN and BAN-Glx with chitosans QS1, CHIT100 and CHIT600. 


\section{REFERENCES}

[1] I. Hamed, F. Özogul, J.M. Regenstein, Industrial applications of crustacean byproducts (chitin, chitosan, and chitooligosaccharides): A review, Trends Food Sci. Tech. 48 (2016) 40-50.

[2] H.K. No, S.P. Meyers, W. Prinyawiwatkul, Z. Xu, Applications of chitosan for improvement of quality and shelf life of foods: a review, J. Food. Sci. 72 (2007) R87-100.

[3] L.J. Foster, S. Ho, J. Hook, M. Basuki, H. Marcal, Chitosan as a biomaterial: Influence of degree of deacetylation on its physiochemical, material and biological properties, PloS one 10 (2015) e0135153.

[4] B.K. Park, M.M. Kim, Applications of chitin and its derivatives in biological medicine, Int. J. Mol. Sci. 11 (2010) 5152-5164.

[5] P. Zou, X. Yang, J. Wang, Y. Li, H. Yu, Y. Zhang, G. Liu, Advances in characterisation and biological activities of chitosan and chitosan oligosaccharides, Food Chem. 190 (2016) 1174-1181.

[6] G.-L. Liu, Y. Li, H.-X. Zhou, Z.-M. Chi, C. Madzak, Over-expression of a bacterial chitosanase gene in Yarrowia lipolytica and chitosan hydrolysis by the recombinant chitosanase, J. Mol. Cat. B: Enz. 83 (2012) 100-107.

[7] K. Azuma, T. Osaki, S. Minami, Y. Okamoto, Anticancer and anti-inflammatory properties of chitin and chitosan oligosaccharides, J. Funct. Biomater. 6 (2015) 3349.

[8] J.Y. Je, S.K. Kim, Chitooligosaccharides as potential nutraceuticals: production and bioactivities, Adv. Food Res. 2012, pp. 321-36.

[9] H. Wu, B.B. Aam, W. Wang, A.L. Norberg, M. Sørlie, V.G.H. Eijsink, Y. Du, Inhibition of angiogenesis by chitooligosaccharides with specific degrees of acetylation and polymerization, Carbohydr. Polym. 89 (2012) 511-518.

[10] A.S. Chen, T. Taguchi, K. Sakai, K. Kikuchi, M.W. Wang, I. Miwa, Antioxidant activities of chitobiose and chitotriose, Biol. Pharm. Bull. 26 (2003) 1326-1330.

[11] J. Simunek, I. Koppova, L. Filip, G. Tishchenko, G. Belzecki, The antimicrobial action of low-molar-mass chitosan, chitosan derivatives and chitooligosaccharides on bifidobacteria, Folia Microbiol. 55 (2010) 379-382.

[12] J.C. Cabrera, P. Van Cutsem, Preparation of chitooligosaccharides with degree of polymerization higher than 6 by acid or enzymatic degradation of chitosan, Biochem. Eng. J. 25 (2005) 165-172.

[13] W.J. Jung, R.D. Park, Bioproduction of chitooligosaccharides: Present and perspectives, Mar. Drugs. 12 (2014) 5328-5356. 
[14] S.N. Hamer, S. Cord-Landwehr, X. Biarnes, A. Planas, H. Waegeman, B.M. Moerschbacher, S. Kolkenbrock, Enzymatic production of defined chitosan oligomers with a specific pattern of acetylation using a combination of chitin oligosaccharide deacetylases, Sci. Rep. 5 (2015) 8716.

[15] D. Pantaleone, M. Yalpani, M. Scollar, Unusual susceptibility of chitosan to enzymic hydrolysis, Carbohydr. Res. 237 (1992) 325-332.

[16] W. Xia, P. Liu, J. Liu, Advance in chitosan hydrolysis by non-specific cellulases, Bioresource Technol. 99 (2008) 6751-6762.

[17] F.S. Kittur, A.B.V. Kumar, L.R. Gowda, R.N. Tharanathan, Chitosanolysis by a pectinase isozyme of Aspergillus niger-A non-specific activity, Carbohydr. Polym. 53 (2003) 191-196.

[18] S.B. Lin, Y.C. Lin, H.H. Chen, Low molecular weight chitosan prepared with the aid of cellulase, lysozyme and chitinase: Characterisation and antibacterial activity, Food Chem. 116 (2009) 47-53.

[19] A.B. Vishu Kumar, R.N. Tharanathan, A comparative study on depolymerization of chitosan by proteolytic enzymes, Carbohydr. Polym. 58 (2004) 275-283.

[20] I. Eş, J.D.G. Vieira, A.C. Amaral, Principles, techniques, and applications of biocatalyst immobilization for industrial application, Appl. Microbio. Biot. 99 (2015) 2065-2082.

[21] J.Y. Song, M. Alnaeeli, J.K. Park, Efficient digestion of chitosan using chitosanase immobilized on silica-gel for the production of multisize chitooligosaccharides, Process Biochem. 49 (2014) 2107-2113.

[22] S. Ichikawa, K. Takano, T. Kuroiwa, O. Hiruta, S. Sato, S. Mukataka, Immobilization and stabilization of chitosanase by multipoint attachment to agar gel support, J. Biosci. Bioeng. 93 (2002) 201-206.

[23] M. Ming, T. Kuroiwa, S. Ichikawa, S. Sato, S. Mukataka, Production of chitosan oligosaccharides by chitosanase directly immobilized on an agar gel-coated multidisk impeller, Biochem. Eng. J. 28 (2006) 289-294.

[24] A. Montilla, A.I. Ruiz-Matute, N. Corzo, C. Giacomini, G. Irazoqui, Enzymatic generation of chitooligosaccharides from chitosan using soluble and immobilized glycosyltransferase (Branchzyme), J. Agric. Food Chem. 61 (2013) 10360-10367.

[25] S. Sinha, S.R. Dhakate, P. Kumar, R.B. Mathur, P. Tripathi, S. Chand, Electrospun polyacrylonitrile nanofibrous membranes for chitosanase immobilization and its application in selective production of chitooligosaccharides, Bioresource Technol. 115 (2012) 152-157. 
[26] L.Y. Zheng, Y.L. Xiao, Penicillium sp. ZD-Z1 Chitosanase immobilized on DEAE cellulose by cross-linking reaction, Korean J. Chem. Eng. 21 (2004) 201-205.

[27] T. Kuroiwa, Y. Noguchi, M. Nakajima, S. Sato, S. Mukataka, S. Ichikawa, Production of chitosan oligosaccharides using chitosanase immobilized on amylose-coated magnetic nanoparticles, Process Biochem. 43 (2008) 62-69.

[28] E.S.M. El-Sayed, S.T. El-Sayed, W.G. Shousha, A.N. Shehata, N.I. Omar, Immobilization, optimization and stability of pepper (Capsicum annuum) chitosanase on chitin, Res. J. Pharm. Biol. Chem. Sci. 7 (2016) 703-711.

[29] H. Lin, H. Wang, C. Xue, M. Ye, Preparation of chitosan oligomers by immobilized papain, Enzyme Microb. Tech. 31 (2002) 588-592.

[30] Y. Wang, C.L. Zhang, P. Li, P.G. Zhou, X.R. Pan, Chitosanase immobilization using composite carrier of sodium alginate/cellulose, Adv. Mat. Res. 236-238 (2011) 2371-2377.

[31] M. Sardar, I. Roy, M.N. Gupta, A smart bioconjugate of alginate and pectinase with unusual biological activity toward chitosan, Biotechnol. Progr. 19 (2003) 1654-1658.

[32] C.H. Kuo, C.C. Chen, B.H. Chiang, Process characteristics of hydrolysis of chitosan in a continuous enzymatic membrane reactor, J. Food Sci. 69 (2004) 332337.

[33] Y.J. Jeon, S.K. Kim, Continuous production of chitooligosaccharides using a dual reactor system, Process Biochem. 35 (2000) 623-632.

[34] T. Kuroiwa, S. Ichikawa, S. Sato, S. Mukataka, Improvement of the yield of physiologically active oligosaccharides in continuous hydrolysis of chitosan using immobilized chitosanases, Biotechnol. Bioeng. 84 (2003) 121-127.

[35] T. Sochi, Non-Newtonian flow in porous media, Polymer 51 (2010) 50075023.

[36] T. Kuroiwa, H. Izuta, H. Nabetani, M. Nakajima, S. Sato, S. Mukataka, S. Ichikawa, Selective and stable production of physiologically active chitosan oligosaccharides using an enzymatic membrane bioreactor, Process Biochem. 44 (2009) 283-287.

[37] Y.J. Jeon, S.K. Kim, Production of chitooligosaccharides using an ultrafiltration membrane reactor and their antibacterial activity, Carbohydr. Polym. 41 (2000) 133-141.

[38] Y.-W. Lin, Y.-C. Hsiao, B.-H. Chiang, Production of high degree polymerized chitooligosaccharides in a membrane reactor using purified chitosanase from Bacillus cereus, Food Res. Int. 42 (2009) 1355-1361. 
[39] S. Sinha, S. Chand, P. Tripathi, Production, purification and characterization of a new chitosanase enzyme and improvement of chitosan pentamer and hexamer yield in an enzyme membrane reactor, Biocatal. Biotransfor. 32 (2014) 208-213.

[40] A.A. Modenbach, S.E. Nokes, Enzymatic hydrolysis of biomass at high-solids loadings - A review, Biomass Bioenerg. 56 (2013) 526-544.

[41] D.R. Picout, S.B. Ross-Murphy, Rheology of biopolymer solutions and gels, Scientific World J. 3 (2003) 105-121.

[42] J. Rakmai, B. Cheirsilp, Continuous production of $\beta$-cyclodextrin by cyclodextrin glycosyltransferase immobilized in mixed gel beads: Comparative study in continuous stirred tank reactor and packed bed reactor, Biochem. Eng. J. 105, Part A (2016) 107-113.

[43] L. Fernandez-Arrojo, P. Santos-Moriano, B. Rodriguez-Colinas, A.O. Ballesteros, F.J. Plou, Micro-scale procedure for enzyme immobilization screening and operational stability assays, Biotechnol. Lett. 37 (2015) 1593-1600.

[44] N. Thadathil, S.P. Velappan, Recent developments in chitosanase research and its biotechnological applications: A review, Food Chem. 150 (2014) 392-399.

[45] X.-A. Gao, W.-T. Ju, W.-J. Jung, R.-D. Park, Purification and characterization of chitosanase from Bacillus cereus D-11, Carbohydr. Polym. 72 (2008) 513-520.

[46] M.M. Bradford, A rapid and sensitive method for the quantitation of microgram quantities of protein utilizing the principle of protein-dye binding, Anal. Biochem. 72 (1976) 248-254.

[47] C.F. de Assis, L.S. Costa, R.F. Melo-Silveira, R.M. Oliveira, M.G. Pagnoncelli, H.A. Rocha, G.R. de Macedo, E.S. Santos, Chitooligosaccharides antagonize the cytotoxic effect of glucosamine, World J. Microbiol. Biotechnol. 28 (2012) 1097-1105.

[48] M. Jiang, Z. Guo, C. Wang, Y. Yang, X. Liang, F. Ding, Neural activity analysis of pure chito-oligomer components separated from a mixture of chitooligosaccharides, Neurosci. Lett. 581 (2014) 32-36.

[49] D.S. Rodrigues, A.A. Mendes, W.S. Adriano, L.R.B. Gonçalves, R.L.C. Giordano, Multipoint covalent immobilization of microbial lipase on chitosan and agarose activated by different methods, J. Mol. Cat. B: Enz. 51 (2008) 100-109.

[50] Z. Zhou, S. Zhao, S. Wang, X. Li, L. Su, Y. Ma, J. Li, J. Song, Extracellular overexpression of chitosanase from Bacillus sp. TS in Escherichia coli, Appl. Biochem. Biotechnol. 175 (2015) 3271-3286.

[51] H.C. Park, M.C. Hawley, R.F. Blanks, The flow of non-Newtonian solutions through packed beds, Polym. Eng. Sci. 15 (1975) 761-773. 
[52] J.J. Stickel, A. Fotopoulos, Pressure-flow relationships for packed beds of compressible chromatography media at laboratory and production scale, Biotechnol. Prog. 17 (2001) 744-751. 


\section{Figure captions}

Figure 1. Optimal temperature of reaction. Soluble BAN was incubated with $1 \%$ $(\mathrm{w} / \mathrm{v})$ chitosan (CHIT100) in $50 \mathrm{mM}$ sodium acetate buffer ( $\mathrm{pH}$ 5.0) at different temperatures $\left(35-80^{\circ} \mathrm{C}\right)$. Relative activity is referred to the maximum value, which is the optimal temperature. Error bars represent standard deviation of three independent measurements.

Figure 2. HPAEC-PAD chromatogram of the reaction of chitosan with BAN. Reaction conditions: $0.5 \%(\mathrm{w} / \mathrm{v})$ chitosan (CHIT100) in $50 \mathrm{mM}$ sodium acetate buffer (pH 5.0), $0.05 \mathrm{U} \mathrm{mL}^{-1} \mathrm{BAN}, 50^{\circ} \mathrm{C}, 900 \mathrm{rpm}, 1.5$ h. Peaks: (1) GlcN; (2) (GlcN) 5 ; (3) $(\mathrm{GlcN})_{4} ;(4)(\mathrm{GlcN})_{3} ;(5)(\mathrm{GlcN})_{2} ;\left({ }^{*}\right)$ unknown.

Figure 3. Quantification of identified deacetylated COS. Reaction conditions: $0.05 \mathrm{U} \mathrm{mL}^{-1}$ BAN (left) or BAN-Glx (right), 0.5\% chitosan (CHIT100), $50 \mathrm{mM}$ acetate buffer $\mathrm{pH} 5.0,50^{\circ} \mathrm{C}, 900 \mathrm{rpm}$.

Figure 4. Enzyme stability at the optimal reaction conditions. BAN and BANGlx were incubated at $50^{\circ} \mathrm{C}$ in $50 \mathrm{mM}$ acetate buffer ( $\mathrm{pH}$ 5.0). Relative activity is referred to the activity previous to any incubation. Error bars represent standard deviation of three independent measurements.

Figure 5. Hydrolysis of chitosan by BAN-Glx in a 100-mL batch reactor. A. Changes in viscosity with reaction time. $\mathbf{B}$. Changes in viscosity related with the formation of COS. Reaction conditions: $1 \%$ CHIT100 in $100 \mathrm{mM}$ acetate buffer (pH 5.0), 1.5 enzyme units. The reactor worked at $50^{\circ} \mathrm{C}$ and $400 \mathrm{rpm}$, with magnetic stirring. Standard deviation of viscosity measurements was lower than $10 \%$.

Figure 6. Dual reactor system. Flow diagram of a hypothetical dual reactor with a CSTR to partially hydrolyze chitosan and a PBR fed with 50\% partially hydrolyzed chitosan for the complete transformation of chitosan into COS.

Figure 7. Effect of dilution rate on the operation of the PBR. Changes in COS concentration (bars), productivity ( $\mathrm{r}_{\mathrm{A}}$, white circles), and conversion yield (black circles) were measured at different flow rates. 
Table 1. Mass spectrometry. Relative intensity of COS and paCOS peaks in the ESI-Q-TOF mass spectra, using different chitosans with soluble (BAN) and immobilized (BAN-Glx) biocatalysts. The order of GlcN/GlcNAc moieties within the paCOS molecules is unknown.

\begin{tabular}{|c|c|c|c|c|c|c|}
\hline \multirow{3}{*}{ COS/paCos } & \multicolumn{6}{|c|}{ Relative intensity of MS peaks } \\
\hline & \multicolumn{2}{|c|}{ QS1a } & \multicolumn{2}{|c|}{ CHIT100b } & \multicolumn{2}{|c|}{ CHIT600c } \\
\hline & BAN & BAN-Glx & BAN & BAN-GIX & BAN & BAN-Glx \\
\hline GlcN & 12.3 & 18.63 & n.d. & n.d. & 1.8 & 7.4 \\
\hline$(\mathrm{GlcN})_{2}$ & 94.5 & 100.0 & 26.1 & 30.8 & 48.8 & 63.4 \\
\hline$(\mathrm{GlcN})_{3}$ & 100.0 & 81.2 & 100.0 & 100.0 & 100.0 & 100.0 \\
\hline$(\mathrm{GlcN})_{4}$ & 2.9 & n.d. & 9.9 & 9.3 & 8.6 & 1.7 \\
\hline GIcN-GIcNAc & n.d. & n.d. & 4.9 & 2.6 & 3.3 & n.d. \\
\hline$(\text { GlcN })_{2}$-GlcNAc & 11.2 & 50.0 & n.d. & n.d. & 1.4 & 11.6 \\
\hline$(\text { GlcN })_{3}$-GlcNAc & 3.9 & 2.58 & n.d. & n.d. & n.d. & 0.80 \\
\hline$(\text { GlcN) })_{4}$-GlcNAc & 1.6 & 0.34 & n.d. & n.d. & n.d. & 0.33 \\
\hline GlcN-(GlcNAc) ${ }_{2}$ & n.d. & 0.47 & n.d. & n.d. & 0.3 & 0.05 \\
\hline$(\mathrm{GlcN})_{2}-(\mathrm{GlcNAc})_{2}$ & 1.4 & 2.05 & n.d. & n.d. & n.d. & 0.32 \\
\hline
\end{tabular}

a MW 98.5 kDa, DD 81\%; b MW 100-300 kDa, DD 290\%; c MW 600-800 kDa, DD $\geq 90 \%$

n.d. not determined

$\underline{\text { Go Back }}$

Table 2. Immobilization of BAN on glyoxal agarose beads.

\begin{tabular}{|c|c|c|c|}
\hline $\begin{array}{c}\text { Glyoxal agarose } \\
\text { (mg) }\end{array}$ & $\begin{array}{c}\text { Initial activity } \\
\text { (U) }\end{array}$ & $\begin{array}{c}\text { Biocatalyst activity } \\
\left(\mathrm{U} \mathrm{g}^{-1}\right)^{\mathrm{a}}\end{array}$ & $\begin{array}{l}\text { Yield }^{b} \\
(\%)\end{array}$ \\
\hline 60 & $0.71 \pm 0.07$ & $2.91 \pm 0.04$ & $25.3 \pm 0.3$ \\
\hline
\end{tabular}

a Measured by the DNS method

b Calculated by dividing the activity recovered in the immobilized biocatalyst by the initial activity offered to the carrier

$\underline{\text { Go back }}$ 
Figure 1

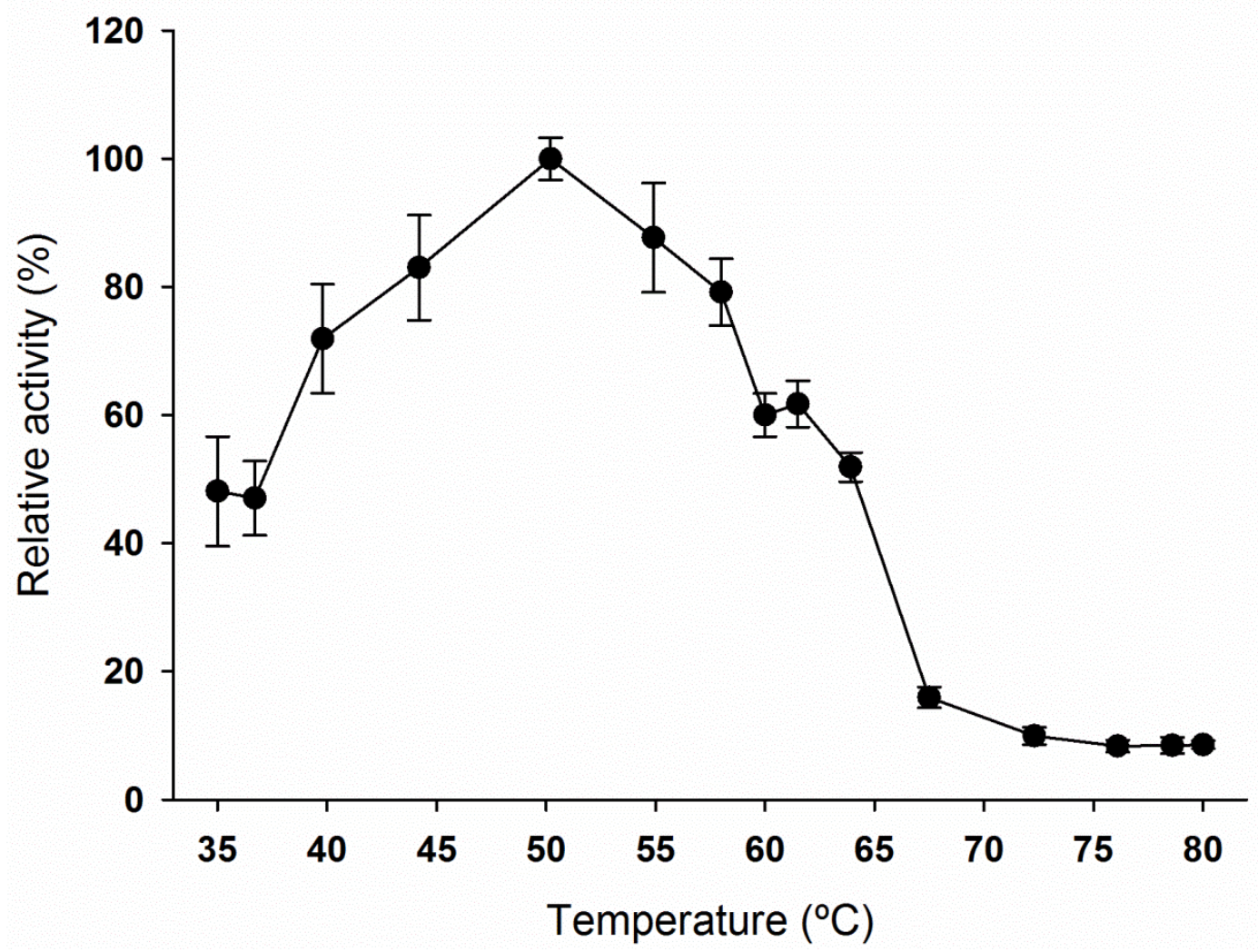

Go back 
Figure 2

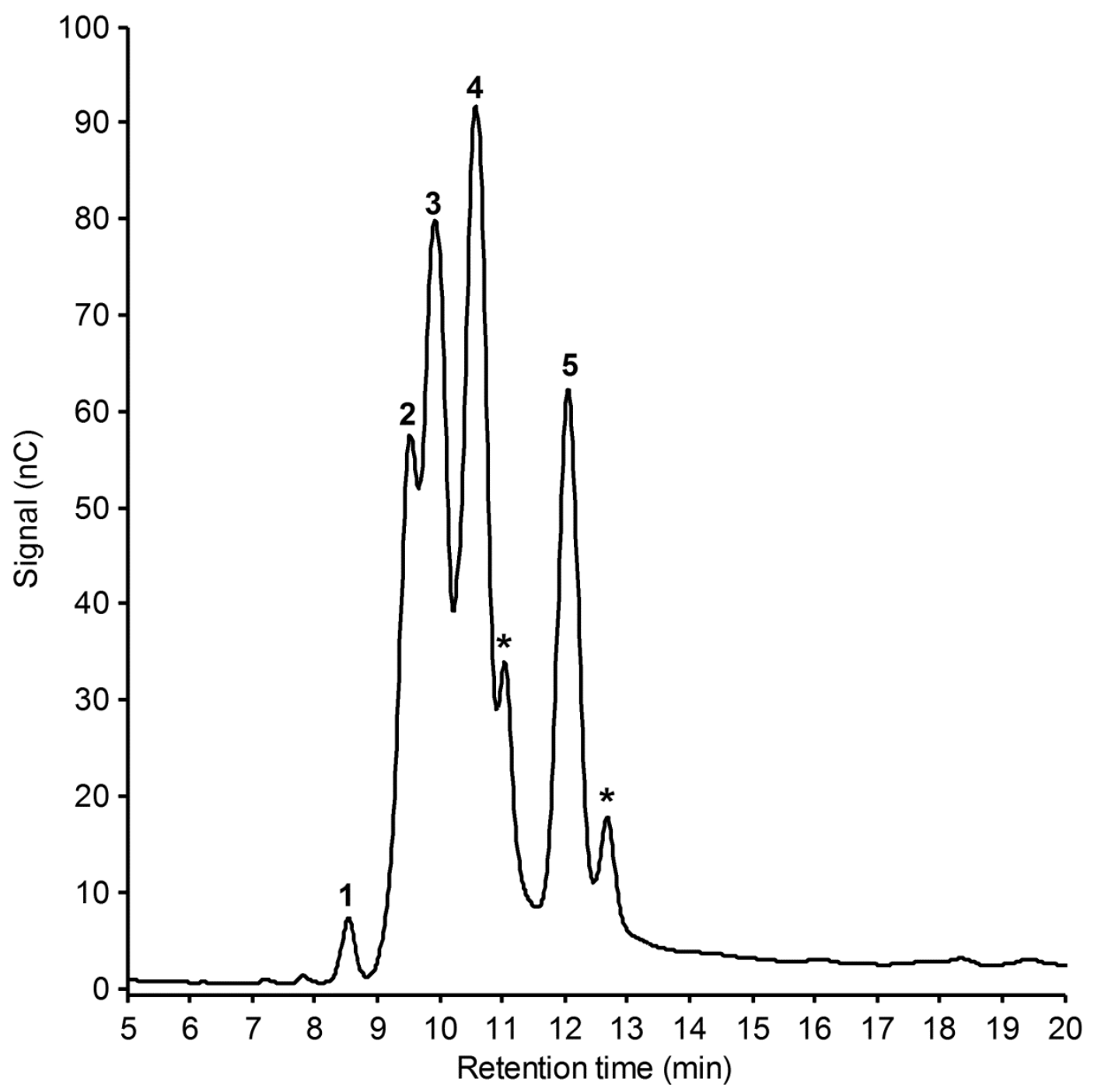

$\underline{\text { Go back }}$ 


\section{Figure 3}
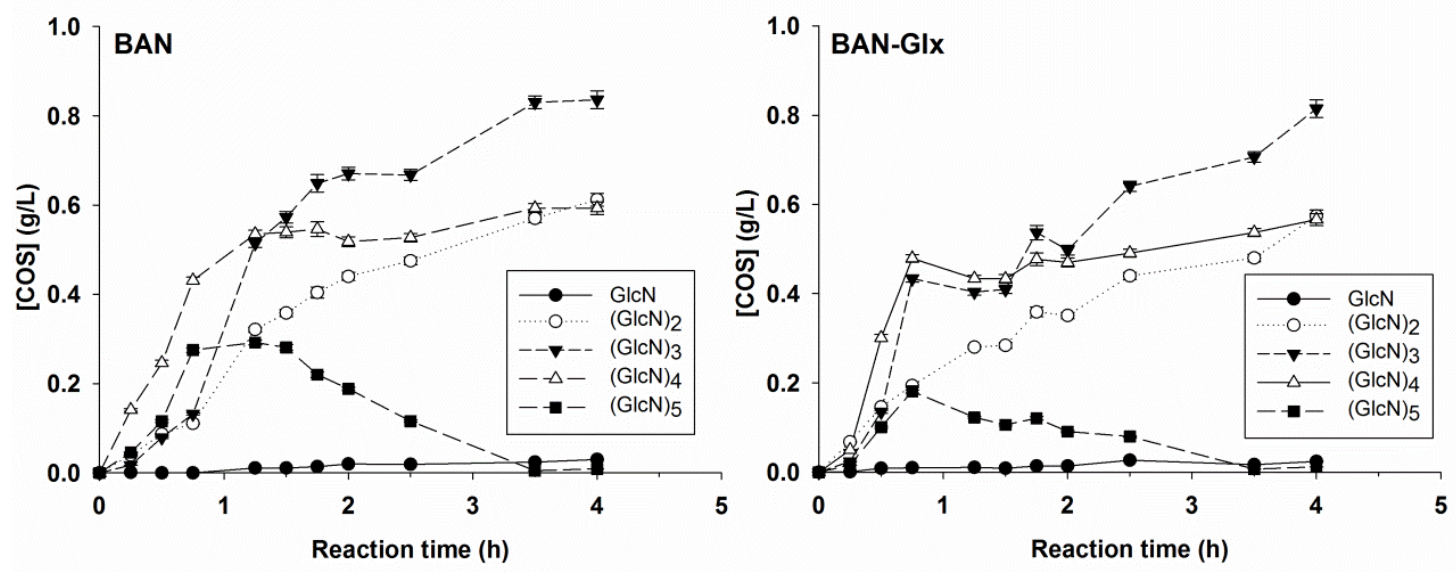

Go back

\section{Figure 4}

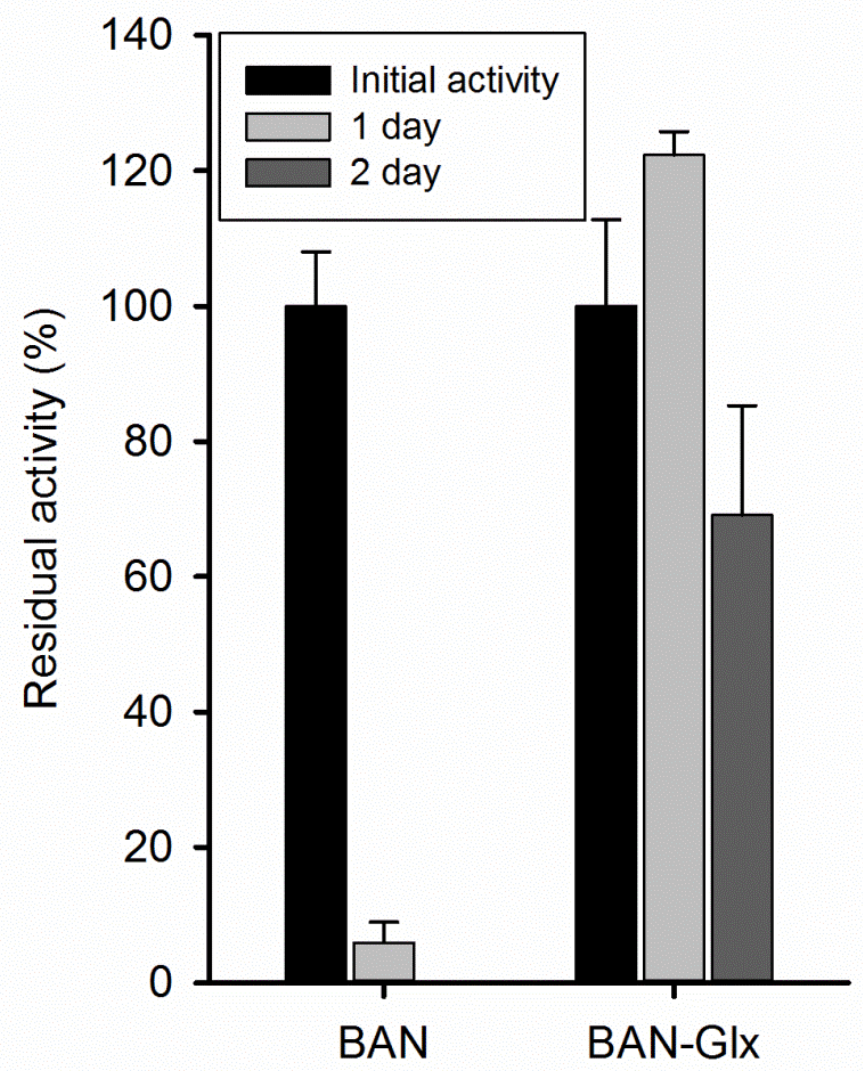

Go back

\section{Figure 5}



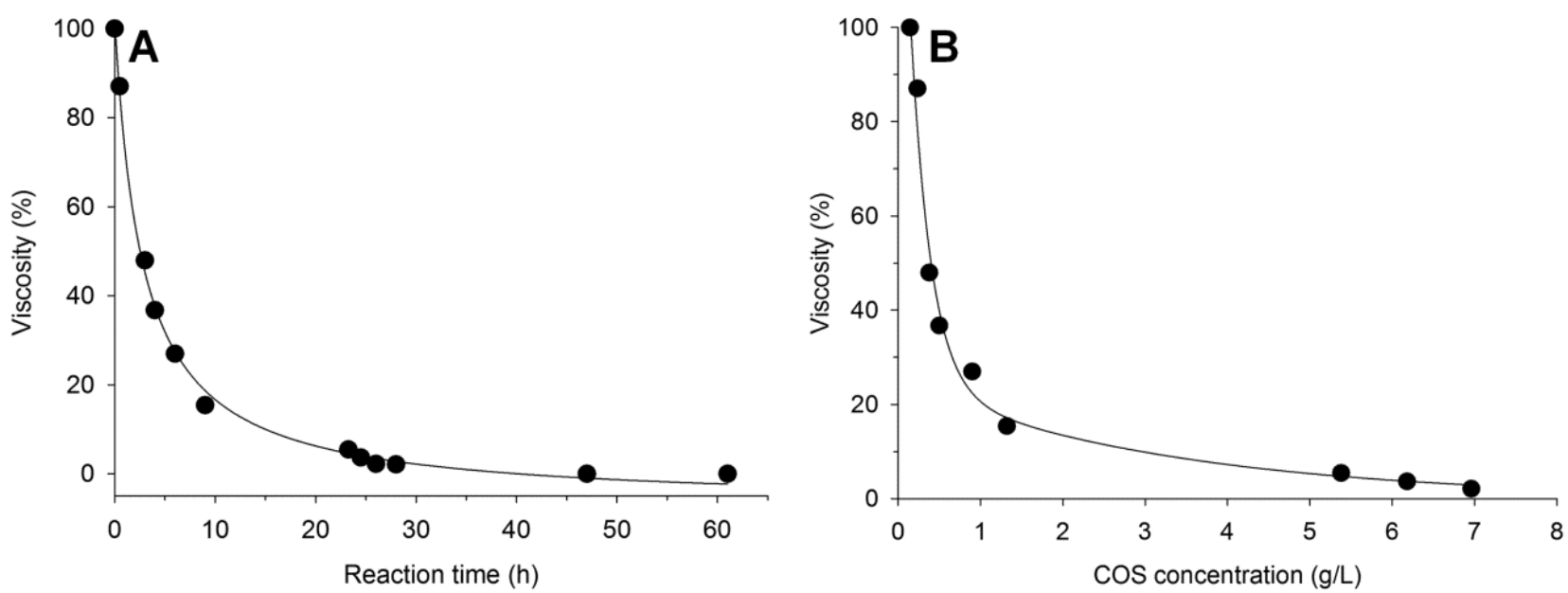

$\underline{\text { Go back }}$

\section{Figure 6}

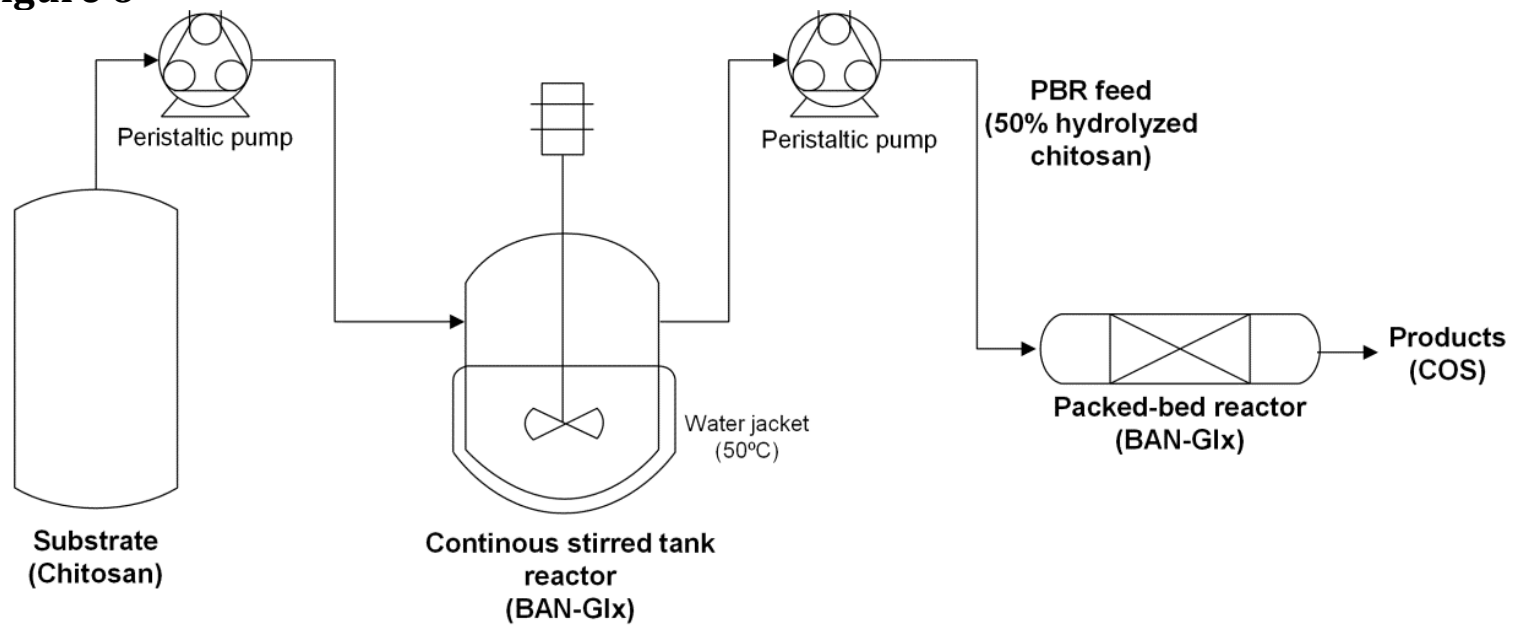

Go back 
Figure 7

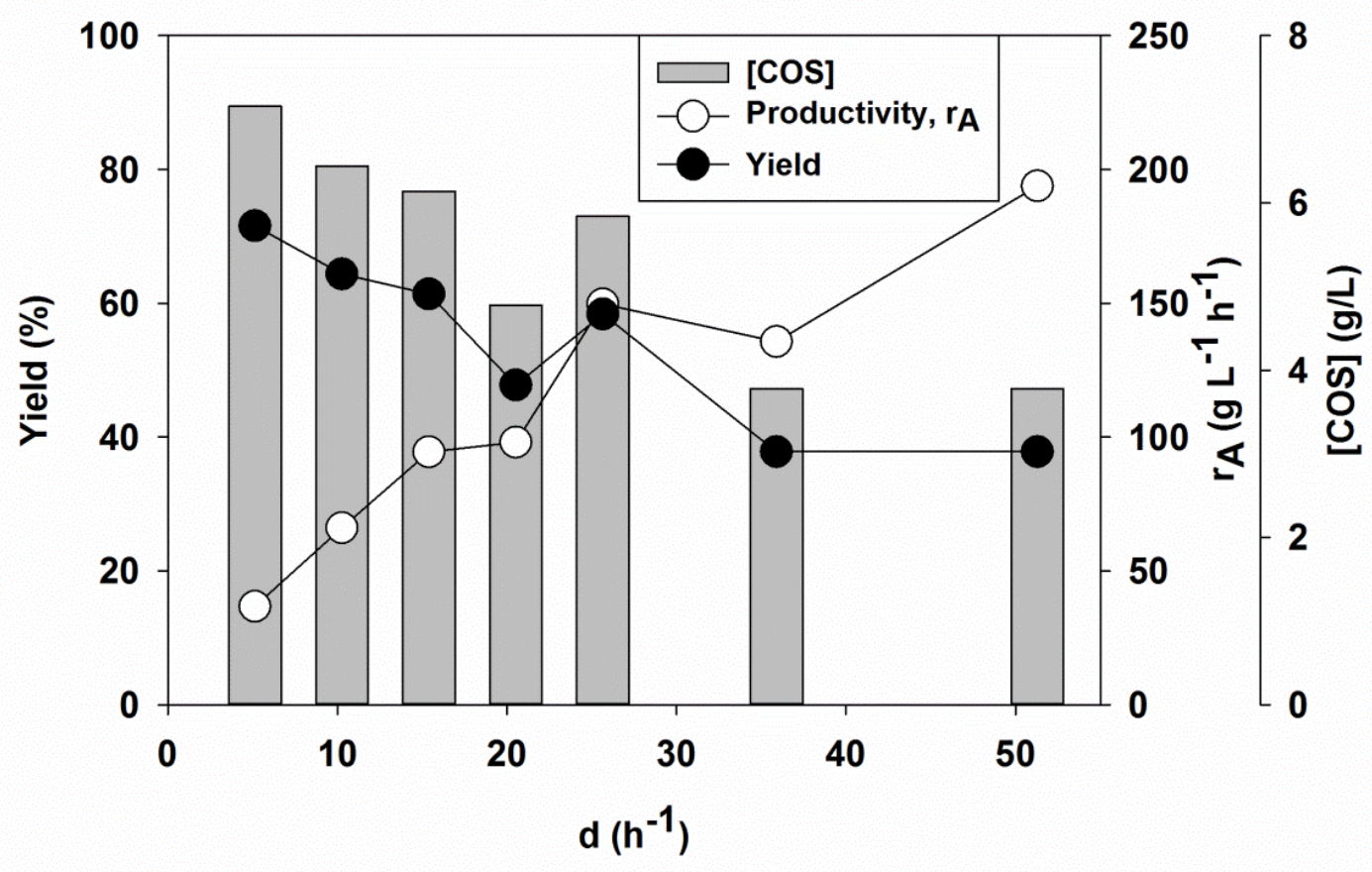

Go back 


\section{Process engineering for the continuous production of chitooligosaccharides (COS) by an immobilized enzyme in a packed-bed reactor}

Paloma SANTOS-MORIANO ${ }^{1}$, John M WOODLEY² and Francisco J PLOU $1{ }^{*}$

${ }^{1}$ Instituto de Catálisis y Petroleoquímica, CSIC, 28049 Madrid, Spain ${ }^{2}$ Department of Chemical and Biochemical Engineering, Technical University of Denmark, 2800 Lyngby, Denmark

* Corresponding author: Francisco J. Plou, Instituto de Catálisis y Petroleoquímica, CSIC, Cantoblanco, Marie Curie 2, 28049 Madrid, Spain. Fax: +34 91 5854760. Email: fplou@icp.csic.es; http://www.franciscoploulab.eu 


\section{Supplementary material}

Figure S1. Protein electrophoresis. 10\% SDS-PAGE. Lanes 1 and 5: molecular weight markers (Precision Plus Protein ${ }^{\mathrm{TM}}$ All Blue Prestained Protein Standards, BioRad, USA). Lanes 2-4 BAN $1.5 \mathrm{mg} / \mathrm{mL}, 0.15 \mathrm{mg} / \mathrm{mL}$ and $0.075 \mathrm{mg} / \mathrm{mL}$, respectively.

Figure S2. MS-ESI spectra of BAN with chitosans QS1 (A), CHIT100 (B) and CHIT600 (C) as substrate; and BAN-Glx with chitosans QS1 (D), CHIT100 (E) and CHIT600 (F) as substrate. 
Fig. S1

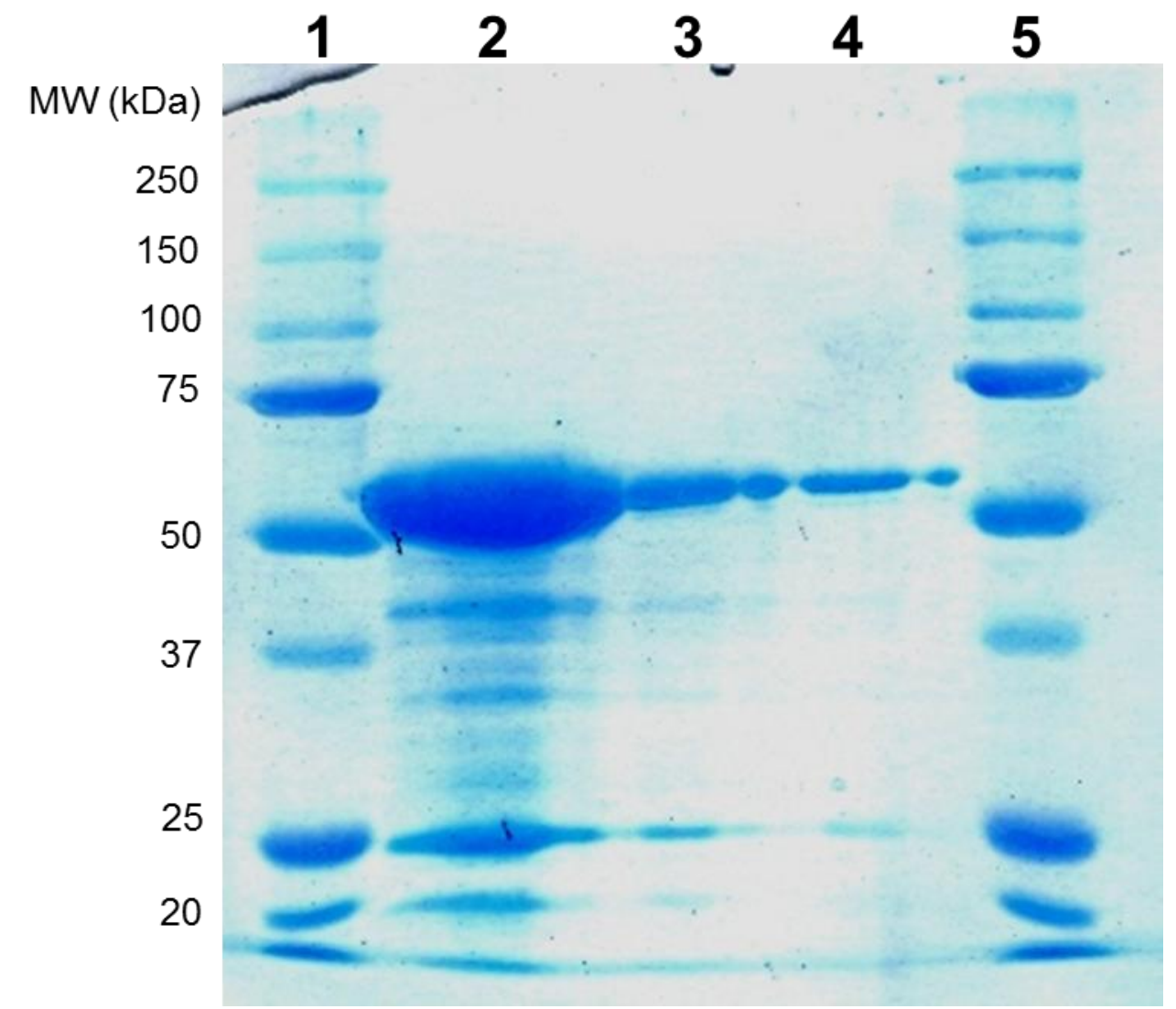

Go back 
Fig. S2

A

+TOF MS: 1.000 to $4.000 \mathrm{~min}$ from QS18535 (recalibrated).wiff
$\mathrm{a}=3.57092640285124880 \mathrm{e}-004, \mathrm{t} 0=4.07259360494376490 \mathrm{e}+001 \mathrm{R}$;

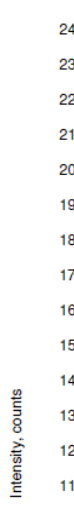

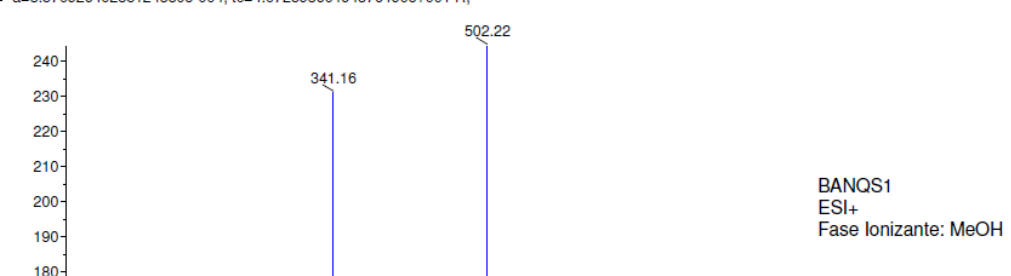

Fase lonizante: $\mathrm{MeOH}$

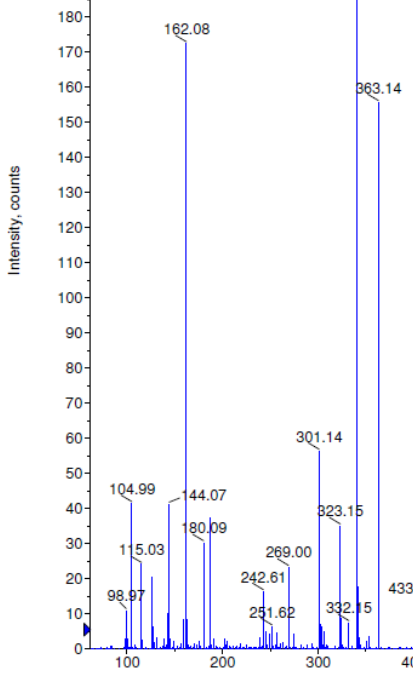

B

+TOF MS: 1.000 to 4.000 min from QS18563 (recalibrated).wiff

Max. 184.7 count

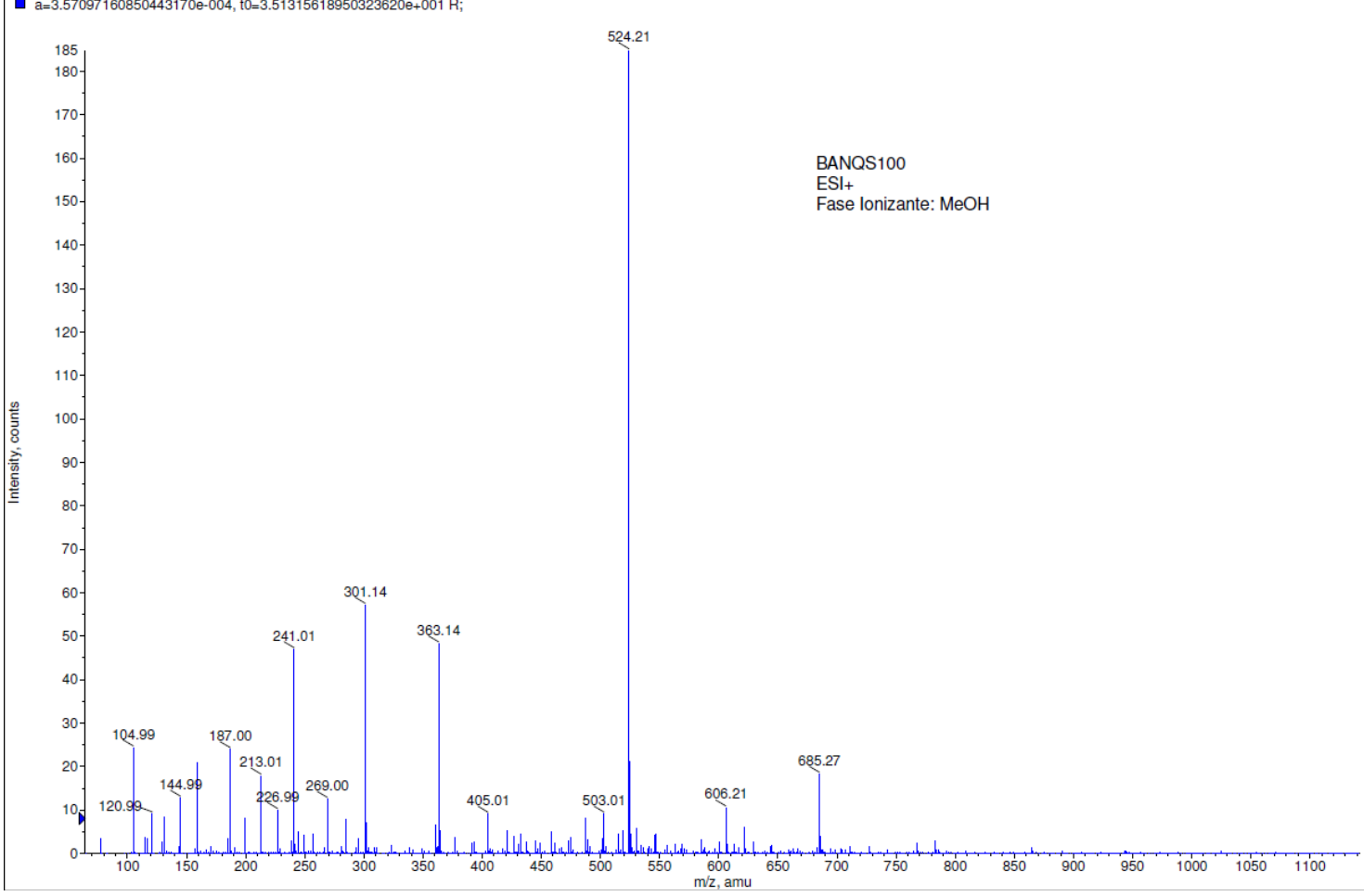


C

+TOF MS: 1.000 to 4.000 min from QS19137 (recalibrated). wiff
$\mathrm{a}=3.57126698903754080 \mathrm{e}-004, \mathrm{t}=4.07584191671988380 \mathrm{e}+001 \mathrm{R}$;

Max. 103.0 counts
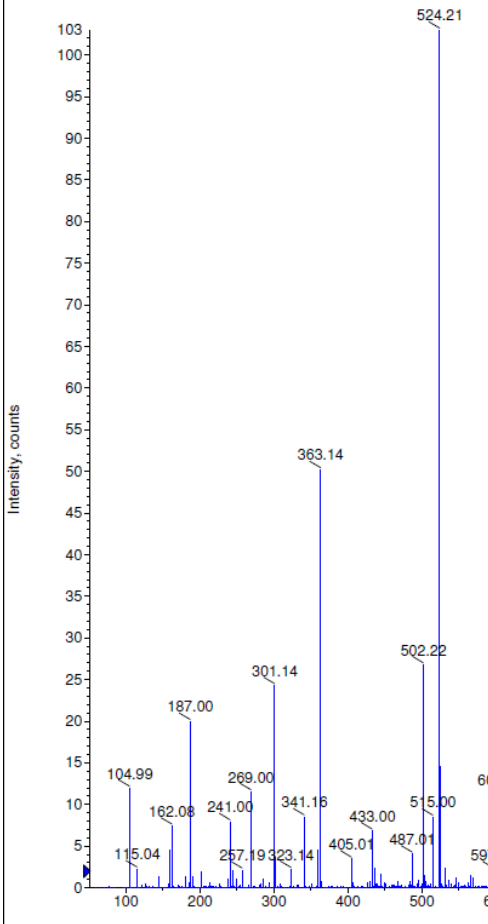

BQS600

ESI+

Fase lonizante: $\mathrm{MeOH}$

D

+TOF MS: 1.000 to 3.000 min from QS21653.wiff
$\mathrm{a}=3.57235834298477810 \mathrm{e}-004, \mathrm{t} 0=3.92756905482856380 \mathrm{e}+001$

Max. 221.3 counts.

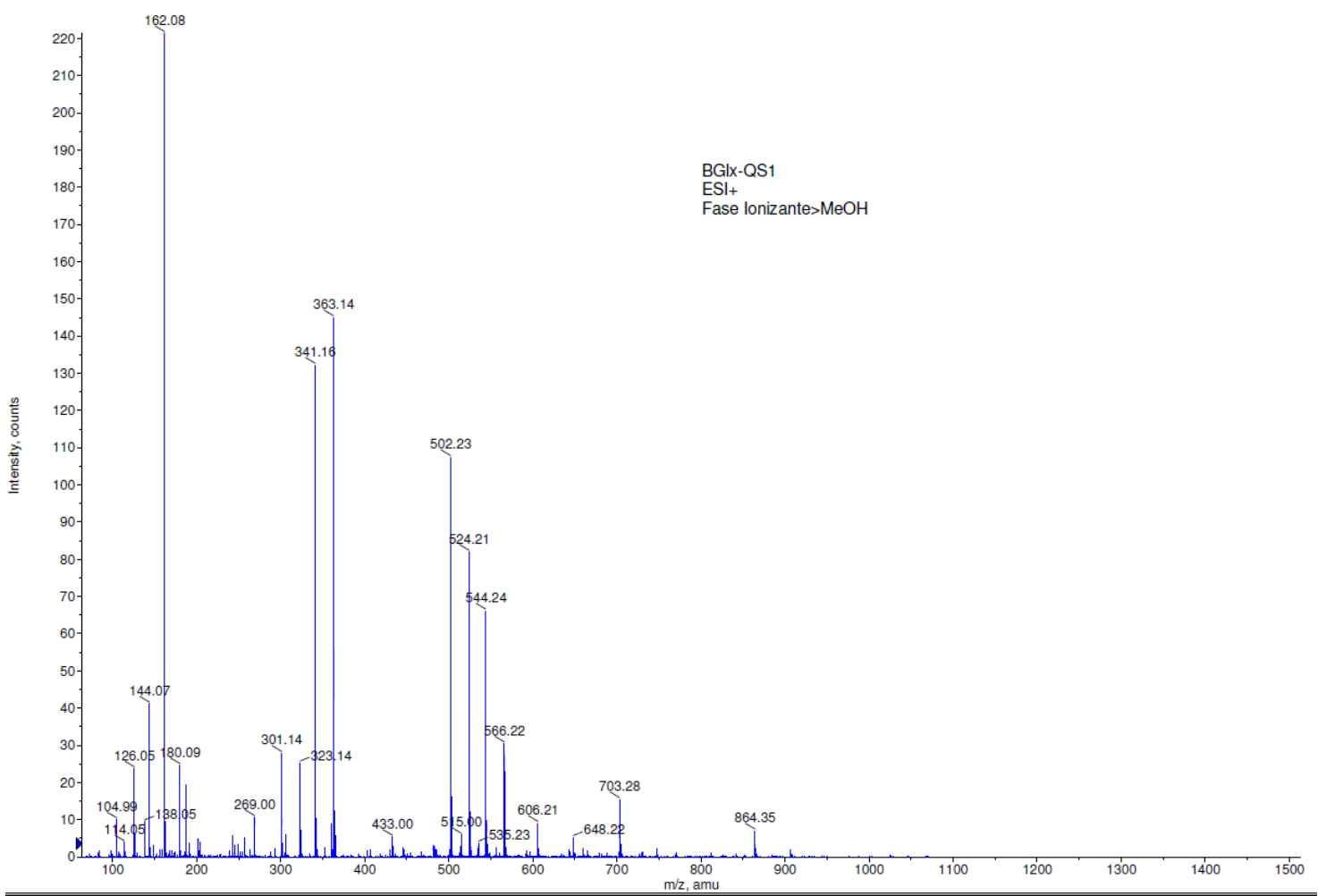




\section{E}

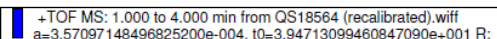

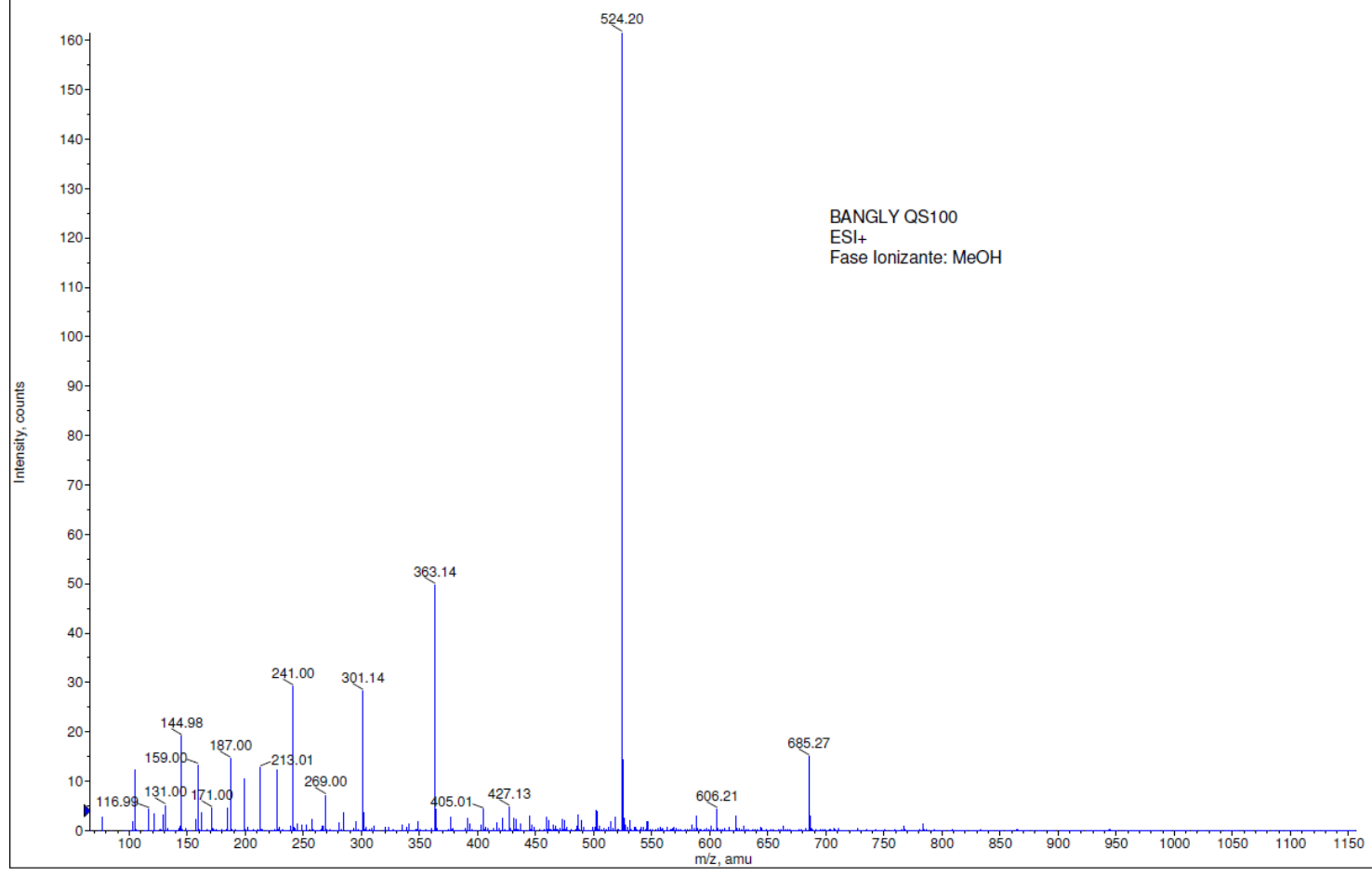

F

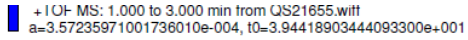

Max. 724.5 counts

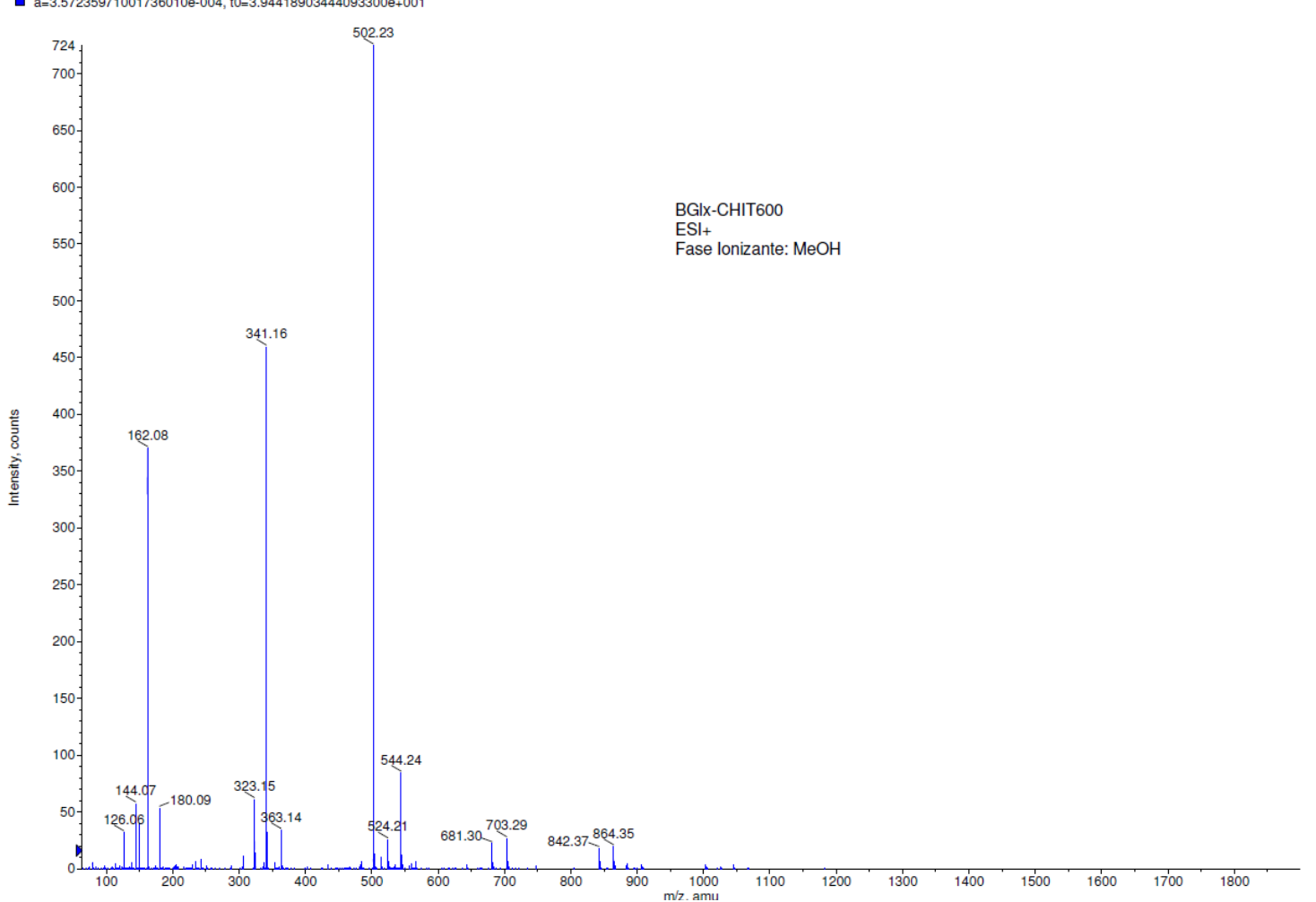

